\title{
Stone composition independently predicts stone size in 18,029 spontaneously passed stones
}

Keller, Etienne Xavier ; De Coninck, Vincent ; Audouin, Marie ; Doizi, Steeve ; Daudon, Michel ;

Traxer, Olivier

\begin{abstract}
PURPOSE To evaluate whether the size of spontaneously passed stones (SPS) may be associated with clinical parameters. METHODS A search for SPS was conducted in our electronic stone database, comprising data on stones analyzed over the last 33 years at our institution. Adults with upper urinary tract stones were included. Cases with stenotic urinary tract disease or past history of anastomotic urinary tract surgery were excluded. Stone size expressed as maximal stone diameter (MSD) and stone volume (SV) was compared between groups by one-way ANOVA. Logistic regression analyses were performed to identify predictors of MSD $6 \mathrm{~mm}$. RESULTS Overall mean MSD and SV for 18,029 SPS was $4.1 \mathrm{~mm}$ and $11.5 \mathrm{~mm}^{3}$, respectively, and significantly differed between stone composition groups $(\mathrm{p}<0.001)$. The lowest mean MSD and SV were found for calcium oxalate monohydrate $(3.6 \mathrm{~mm}$ and $9.0 \mathrm{~mm}^{3}$, respectively) and the highest mean MSD and SV were found for struvite (7.9 $\mathrm{mm}$ and 61.0 $\mathrm{mm}^{3}$, respectively). Stone composition and increasing age were found to be independent predictors of MSD $6 \mathrm{~mm}$ (both $\mathrm{p}<0.001$ ). Sex differentiation did not contribute as a predictor of MSD $6 \mathrm{~mm}$. CONCLUSIONS Stone composition and-to a lesser extent-age serve as independent predictors of size of spontaneously passed stones. Of particular importance, large spontaneously passed stones of $6 \mathrm{~mm}$ may be frequently found in cystine, brushite or struvite stone formers, whereas a minority of all calcium oxalate stones exceed that cutoff. Future studies shall evaluate these parameters as possible predictors of spontaneous stone passage.
\end{abstract}

DOI: https://doi.org/10.1007/s00345-018-02627-0

Posted at the Zurich Open Repository and Archive, University of Zurich ZORA URL: https://doi.org/10.5167/uzh-182808

Journal Article

Accepted Version

Originally published at:

Keller, Etienne Xavier; De Coninck, Vincent; Audouin, Marie; Doizi, Steeve; Daudon, Michel; Traxer, Olivier (2019). Stone composition independently predicts stone size in 18,029 spontaneously passed stones. World Journal of Urology, 37(11):2493-2499.

DOI: https://doi.org/10.1007/s00345-018-02627-0 


\section{Stone Composition independently predicts Stone Size in 18'029 Spontaneously Passed Stones}

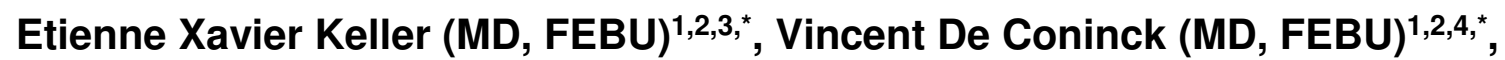
Marie Audouin (MD) $)^{1,2}$, Steeve Doizi (MD, MSc) ${ }^{1,2}$, Michel Daudon (PhD) ${ }^{5,6,7}$, Olivier Traxer (MD) $)^{1,2}$

1. Sorbonne Université, Service d'Urologie, AP-HP, Hôpital Tenon, F-75020 Paris, France

2. Sorbonne Université, GRC n²0, Groupe de Recherche Clinique sur la Lithiase Urinaire, Hôpital Tenon, F-75020 Paris, France

3. Department of Urology, University Hospital Zurich, Zurich, Switzerland

4. Department of Urology, AZ Klina, Brasschaat, Belgium

5. CRISTAL Laboratory, Tenon Hospital, Paris, France

6. Laboratoire des Lithiases, Service des Explorations Fonctionnelles Multidisciplinaires, AP-HP, Hôpital Tenon, Paris, France

7. INSERM, UMRS 1155 UPMC, Tenon Hospital, Paris, France

* These authors contributed equally

\section{CORRESPONDING AUTHOR:}

Prof. Olivier Traxer, MD

Service d'Urologie, Hôpital Tenon, Assistance-Publique Hôpitaux de Paris 4 rue de la Chine, 75020 Paris, France

Phone : (+33) 156016153

Fax : (+33) 156016377

Email : olivier.traxer@aphp.fr

\section{KEYWORDS:}

Urinary stone, stone size, stone composition, spontaneous passage, age, recommendations, adults

WORD COUNT:

Word count of text: 2508

Abstract: 245 


\section{Abstract}

Purpose: To evaluate whether size of spontaneously passed stones (SPS) may be associated with clinical parameters.

Methods: A search for SPS was conducted in our electronical stone database, comprising data on stones analyzed over the last 33 years at our institution. Adults with upper urinary tract stones were included. Cases with stenotic urinary tract disease or past history of anastomotic urinary tract surgery were excluded. Stone size expressed as maximal stone diameter (MSD) and stone volume (SV) was compared between groups by one-way ANOVA. Logistic regression analyses were performed to identify predictors of MSD $\geq 6 \mathrm{~mm}$.

Results: Overall mean MSD and SV for $18^{\prime} 029$ SPS was $4.1 \mathrm{~mm}$ and $11.5 \mathrm{~mm}^{3}$, respectively, and significantly differed between stone composition groups $(p<0.001)$. Lowest mean MSD and SV was found for calcium oxalate monohydrate $(3.6 \mathrm{~mm}$ and $9.0 \mathrm{~mm}^{3}$, respectively) and highest mean MSD and SV was found for struvite (7.9 $\mathrm{mm}$ and $61.0 \mathrm{~mm}^{3}$, respectively). Stone composition and increasing age were found as independent predictors of MSD $\geq 6 \mathrm{~mm}$ (both $p<0.001$ ). Sex differentiation did not contribute as a predictor of MSD $\geq 6 \mathrm{~mm}$.

Conclusions: Stone composition and - to a lesser extent - age serve as independent predictors of size of spontaneously passed stones. Of particular importance, large spontaneously passed stones of $\geq 6 \mathrm{~mm}$ may be frequently found in Cystine, Brushite or Struvite stone formers, whereas a minority of all Calcium oxalate stones exceed that cut-off. Future studies shall evaluate these parameters as possible predictors of spontaneous stone passage. 


\section{Introduction}

Urinary stone disease is a widespread medical condition with an annual incidence of symptomatic stone events of $0.1-0.4 \%$ and a recurrence rate of $>50 \%$ within 10 years [1]. It is estimated that 64 to $78 \%$ of ureteral stones are spontaneously expulsed $[2,3]$. The remaining stones are either fragmented by extracorporeal shockwave lithotripsy or actively withdrawn by endourological techniques such as ureteroscopy and percutaneous nephrolithotomy.

The probability for spontaneous passage of ureteral stones follows an almost linear relationship with stone size [4,5]. Based on a computed tomography (CT) study, spontaneous stone passage rates were $78 \%, 60 \%$ and $39 \%$ for stones $<5 \mathrm{~mm}, 5-7$ $\mathrm{mm}$ and $>8 \mathrm{~mm}$, respectively [6]. Stone size has also been associated with time to spontaneous stone passage, resulting in an average of 8,12 and 22 days for passage of ureteral stones of 2,3 and $4-6 \mathrm{~mm}$, respectively [7]. This relationship forms the rationale for international guidelines recommending conservative treatment based on maximal stone diameter (MSD) [8-10]. Another predictor of spontaneous stone passage is stone location at diagnosis, with passage rates of $45-75 \%, 22-60 \%$ and $12-48 \%$ for distal, mid and proximal ureter stones, respectively $[4,6]$. Individual characteristics such as persistent pain, renal insufficiency, signs of infection and comorbidities should also be considered for treatment decision.

Altogether, only sparse data regarding spontaneous stone passage according to stone size are available to date [11]. Particularly, only few studies to date have considered the relationship between the size of spontaneously passed stones (SPS) and patient or stone clinical factors such as age, sex and stone composition $[7,12,13]$. Further evaluation of these parameters could provide novel insights that may ultimately impact on recommendations for conservative stone treatment. 
In the present study, a search for predictors of size of SPS was conducted in our stone database, including a differentiation for the eight most common stone compositions. 


\section{Patients and methods}

\section{Study design}

A search for SPS was conducted in our electronic stone database in May 2018. This database was built over the last 33 years at our institution $(1985-2018)$ in Paris. It contains data on clinical, morphological and constitutional characteristics of stones originating from France. Patient data were provided by the referring clinician and stone analysis was performed at our institution. Only stones for which no operative treatment was necessary were coded as SPS. All SPS originating from adults and labelled as upper urinary tract stones at the time of diagnosis were considered for this study. Cases with documented stenotic urinary tract disease or with past history of anastomotic urinary tract surgery were excluded. Age and sex were retrieved for each case. Stones were classified according to a methodology previously described by M.D. [14]. This included the analysis of various parts of each stone for determination of the main crystalline constituent ( $\geq 50-100 \%$ of total constituent). Stone constituents were ordered after the Daudon classification, from which the eight most frequent main crystalline constituents (thereafter called stone composition) were selected for analysis: calcium oxalate monohydrate (COM), calcium oxalate dihydrate (COD), anhydrous uric acid (UA0), uric acid dihydrate (UA2) carbapatite (CA), struvite (STR), brushite (BR) and cystine (CYS) [15].

\section{Outcomes}

Primary outcome was stone size, as measured by maximal stone diameter (MSD) and stone volume (SV). Stone volume was calculated by the formula of an ellipsoid: 4/3 $\times \mathrm{Pi} \times \mathrm{A} \times \mathrm{B} \times \mathrm{C}$, where $\mathrm{A}, \mathrm{B}$ and $\mathrm{C}$ corresponded to maximal stone radii in three dimensions, respectively. All measurements were done on tangible stones using a metric caliper. Whenever more than two SPS were available per case, characteristics 
of the SPS with the largest MSD were considered. Substrates for stone size were generated using a MSD cut-off of $6 \mathrm{~mm}$ in order to address predictors for stones that are not considered to have a high likelihood of spontaneous passage according to the current guidelines of the European Association of Urology (EAU) [8].

\section{Statistical analysis}

Primary outcome as well as other continuous variables were analyzed using Pearson's correlation coefficient, Student's t-test and one-way ANOVA with Tukey post hoc comparisons, as appropriate. For stone volume, geometric mean values were reported. Logistic regression analyses were performed to identify predictors of MSD $\geq 6 \mathrm{~mm}$. Association between categorical variables was evaluated by the Chisquare test or Fischer's exact test, as appropriate. All statistical tests were two-sided and $p$-values $<0.05$ were considered significant. Statistical analysis and graph plotting were performed with IBM SPSS Statistics 24.0 (IBM Corp., Armond, NY, USA). 


\section{Results}

From 80 '253 stones listed in the database, a total of $19^{\prime} 139$ were labelled as SPS and 18'029 were available for analysis (Supplementary Figure 1). Patient and stone characteristics are summarized in Table 1, including a stratification for stone composition. Overall mean age was 45 years (standard deviation (SD) 14) and significantly differed between males (46 years, SD 14) and females (44 years, SD 15) $(p<0.001)$. Mean age also significantly differed over stone composition groups $(p<0.001)$ (Table 1). The distribution of cases over age according to sex and stone composition is presented in Figure 1-A and Figure 1-B, respectively. The predominant stone composition was COM over all age groups. The proportion of COD stones decreased with age, whereas the proportions of UA0 and UA2 stones increased with age. The highest proportions of STR was found in the oldest age group, whereas the highest proportion for CYS was in the youngest age group. There was a majority of male cases over all stone composition categories, except for CA which included a majority of female cases (male/female ratio 0.88 ) and STR which included an equal number of male and female cases (ratio 1.00) (Table 1).

\section{Comparisons for stone size}

Mean overall MSD was $4.1 \mathrm{~mm}$ (SD 2.2) and mean overall SV was $11.5 \mathrm{~mm}^{3}(\mathrm{SD}$ 3.5). Increasing age significantly correlated with increasing MSD $(r=0.15, p<0.001)$, and increasing SV $(r=0.17, p<0.001)$. Males showed significantly lower mean MSD and mean SV compared to females $\left(4.0 \mathrm{~mm}\right.$ versus $4.1 \mathrm{~mm}, p=0.01$ and $11.2 \mathrm{~mm}^{3}$ versus $12.3 \mathrm{~mm}^{3}, p<0.001$, respectively).

Mean MSD differed significantly between stone composition categories $(p<0.001)$ (Figure 2-A). The lowest mean MSD was found for COM (3.6 mm, 95\% Cl 3.5-3.6) and significantly differed from all other stone categories in a post hoc analysis: 4.5 
$\mathrm{mm}$ for $\mathrm{COD}$ (95\% Cl 4.4-4.6), $5.5 \mathrm{~mm}$ for UA0 (95\% Cl 5.3-5.6), $4.6 \mathrm{~mm}$ for UA2 (95\% Cl 4.3-4.9), $4.9 \mathrm{~mm}$ for CA (95\% Cl 4.8-5.0), $7.9 \mathrm{~mm}$ for STR (95\% Cl 6.9-9.0), $6.2 \mathrm{~mm}$ for $\mathrm{BR}(95 \% \mathrm{Cl} 5.8-6.6)$ and $6.8 \mathrm{~mm}$ for $\mathrm{CYS}(95 \% \mathrm{Cl} 6.2-7.5)(p<0.001$ for all).

Mean SV also differed significantly between stone composition categories $(p<0.001)$ (Figure 2-B). The lowest mean SV was found for COM $\left(9.0 \mathrm{~mm}^{3}, 95 \% \mathrm{Cl} 8.8-9.2\right)$ and significantly differed from all other stone categories in a post hoc analysis: 14.0 $\mathrm{mm}^{3}$ for $\operatorname{COD}(95 \% \mathrm{Cl} 13.4-14.6), 21.0 \mathrm{~mm}^{3}$ for UAO (95\% Cl 19.6-22.6), $12.0 \mathrm{~mm}^{3}$ for UA2 (95\% Cl 10.2-14.1), $18.3 \mathrm{~mm}^{3}$ for CA (95\% Cl 17.0-19.7), $61.0 \mathrm{~mm}^{3}$ for STR (95\% Cl 40.5-91.8), $39.4 \mathrm{~mm}^{3}$ for $\mathrm{BR}(95 \% \mathrm{Cl} 32.9-47.2)$ and $42.1 \mathrm{~mm}^{3}$ for $\mathrm{CYS}$ (95\% Cl 32.7-54.2) ( $p \leq 0.001$ for all).

\section{Comparisons considering a stone size cut-off}

Out of the $18^{\prime} 029$ stones available for analysis, 3'166 (18\%) had a MSD $\geq 6 \mathrm{~mm}$. The proportion of stones with a MSD $\geq 6 \mathrm{~mm}$ significantly differed between stone composition groups $(p<0.001): 10 \%$ for COM, followed by $25 \%$ for COD, $26 \%$ for UA2, $29 \%$ for CA, $38 \%$ for UA0, $53 \%$ for $\mathrm{BR}, 55 \%$ for $\mathrm{CYS}$ and $65 \%$ for STR (Supplementary Figure 2). In a logistic regression analysis, age and stone composition were found as independent predictors for SPS $\geq 6 \mathrm{~mm}$ (Table 2). For increments of 10 years of age, the adjusted odds ratio (OR) for a SPS $\geq 6 \mathrm{~mm}$ was $1.37(95 \% \mathrm{Cl} 1.33-1.41 ; p<0.001)$. As for stone composition, the adjusted OR for SPS $\geq 6 \mathrm{~mm}$ was lowest for UA2 (OR 2.5, 95\%Cl 1.9-3.2; $p<0.001)$ and highest for STR (OR 17.1, 95\% Cl 9.1-32.4; $p<0.001$ ), respectively, when compared to COM. 


\section{Comparisons for age subgroups}

A significant interaction was found between stone composition and age after the addition of multiplicative interaction terms in the multivariate logistic regression analysis for MSD $\geq 6 \mathrm{~mm}$ ( $p<0.001$, data not shown). This prompted us to verify whether the distribution of stones $\geq 6 \mathrm{~mm}$ over age groups would vary according their stone composition. A significant association was found between stone size (cut-off 6 $\mathrm{mm})$ and age (grouped by decades) for COM ( $p<0.001), \operatorname{COD}(p<0.001), \mathrm{CA}$ $(p<0.001)$ and CYS $(p=0.017)$, whereas no evidence for such association was found for UA0 ( $p=0.14)$, UA2 $(p=0.33)$, STR $(p=0.74)$ and BR $(p=0.53)$ (Supplementary Figure 3). 


\section{Discussion}

Stone size and stone location have been repeatedly reported as predictors of spontaneous stone passage in currently available literature $[5,16,4,7,6,17-19,3]$.

Remarkably, no prior study to date evaluated predictors of the size of SPS expressed as MSD and SV. In the present study, characteristics of 18 '029 SPS were analyzed and stone composition was found as a major, independent predictor of stone size. Patients' age also contributed as an independent predictor of stone size, although with lower odds than stone composition. Sex differentiation did not contribute as a significant predictor of stone size.

Few studies on natural history of stone expulsion detailed the overall mean MSD of SPS, which ranged between 5.4 to $6.3 \mathrm{~mm}[5,19,12]$. In another study, only 47 out of 566 SPS (8\%) were found to have a MSD $\geq 6 \mathrm{~mm}$. In those studies, stone size measurements where based on plain radiographs or CT scans. The latter measurements are subject to inaccuracy and may not adequately reflect true stone size parameters [20]. In contrast, measurements were performed on tangible stones in this study, resulting in an overall mean MSD of $4.1 \mathrm{~mm}$, with $18 \%$ of all SPS having a MSD $\geq 6 \mathrm{~mm}$. Also, each stone was measured in 3 axes, resulting in an overall mean SV of $11.5 \mathrm{~mm}^{3}$. To the best of our knowledge, this is the first report on SPS including SV measurements.

In studies evaluating the natural history of conservatively managed ureteral stones, neither age nor sex contributed as a predictor of spontaneous passage $[19,7,18]$. Based on the current findings, the odds predicting a SPS $\geq 6 \mathrm{~mm}$ significantly increased by 1.37 for every increase in 10 years of age, whereas no association was found with sex. In subgroup analyses, the relationship between age and stone size was found to be particularly valid for COM, COD, CA and CYS stones. Of interest, 
the distribution of stone composition over age groups adhered to observations found in prior reports [2,21]. COM stones were predominant in all age groups, whereas the proportion of COD stones decreased with age and UA stones increased with age.

Most importantly, significant size differences were found between stone compositions. Of all stone compositions, COM and COD stones showed the lowest mean MSD (3.6 $\mathrm{mm}$ and $4.5 \mathrm{~mm}$, respectively) and the lowest and second-lowest mean SV $\left(9.0 \mathrm{~mm}^{3}\right.$ and $14.0 \mathrm{~mm}^{3}$, respectively). These two stone compositions accounted for the vast majority (81\%) of all SPS, in accordance to current reports on overall stone prevalence in European countries [2]. Importantly, 90\% of COM and $75 \%$ of COD stones had a MSD $<6 \mathrm{~mm}$. Hence, a majority of all calcium-oxalate stones fell within the current EAU guidelines on urolithiasis, which consider stones $<6$ $\mathrm{mm}$ to have a high likelihood of spontaneous passage $[8,9]$. Comparatively, more than a quarter of all UA stones and more than half of all BR and CYS stones surpassed the $6 \mathrm{~mm}$ cut-off. The largest stone size was found for STR stones (mean MSD $7.9 \mathrm{~mm}$, mean SV $61 \mathrm{~mm}^{3}$ ). Because the latter stone type is typically associated with urinary tract infection [22], active stone removal should be considered irrespective of stone size. This may well explain why only a low number of spontaneously passed STR stones was found in our stone database.

Two distinct scenarios or the combination thereof may explain the association of age and stone composition with size of SPS. First, size differences may be attributable to relative stone growth rate, which may be higher in older patients as a consequence of reduced thirst and fluid intake [23], and which may differ between stone compositions. Consequently, at a constant probability of stone displacement from kidneys towards the ureters, the probability for a larger stone to reach the ureters would be high in case of rapid stone growth. Accordingly, relative stone growth rate 
would be highest for CYS, BR and STR, which were also found to have the lowest rate of spontaneous expulsion in a previous evaluation based on our stone database, thus supporting this first hypothesis [2]. Second, size differences may be attributable to anatomical differences, with larger ureters in stone formers with high recurrence rate as a consequence of repeated ureteral obstruction and dilation. Of interest, stone composition has recently been linked with stone recurrence, with a minority of COM and COD as well as a majority of BRU and CYS presenting as recurrent stone formers, respectively, thus matching this second hypothesis with our results [24].

Three stone compositions deserve particular attention, because their composition may be predicted based on clinical parameters and patients' past history. First, UA stones have been associated with metabolic syndrome, are radiolucent, have a low Hounsfield count on CT imaging and typically occur in the older population, as confirmed in this study $[25,21,26]$. Second, BR stones have been associated with hypercalciuria and hyperparathyroidism, and have been repeatedly showed to have the highest mean Hounsfield count on CT imaging $[27,26,28,22,29]$. Third, CYS stones can easily be predicted whenever cystinuria has been readily diagnosed. Considering the above, it could be that a larger stone size cut-off for conservative treatment may be considered whenever UA, BR or CYS stones are suspected.

A limitation to this study was the lack of data which would have allowed calculation of the rate of spontaneous stone passage and the predictors thereof. This would necessitate the observation of newly diagnosed patients over time and must be addressed in future studies. Time from diagnosis to passage was not known and may account as a confounder, since time accorded for conservative treatment may be associated with age due to concern with surgery. Several other parameters were not available for analysis and may have contributed as cofounders: history of prior stone 
passage or stone surgery, medical expulsive therapy, proportion of SPS retrieved for analysis and stone alterations during expulsion or collection. Despite these limitations, the strength of this study is the considerable number of SPS, which arguably may mitigate the impact that cofounders might have had on results. This study might simulate future research to develop a more personalized treatment plan and follow up for recurrent stone former based on their age and stone composition.

\section{Conclusions}

Stone composition is a strong and independent predictor of size of SPS. A minority of all COM and COD stones surpass $6 \mathrm{~mm}$ in maximal diameter, whereas a majority of $\mathrm{BR}, \mathrm{CYS}$ and STR stones exceed that cut-off. To a lesser extent, age also serves as an independent predictor of stone size of SPS. Future studies shall evaluate these parameters as possible predictors of spontaneous stone passage. 


\section{Disclosures}

Olivier Traxer is a consultant for Coloplast, Rocamed, Olympus, EMS and Boston

Scientific. Steeve Doizi is a consultant for Coloplast.

Etienne Xavier Keller is supported by a Travel Grant from the University Hospital Zurich and from the Kurt and Senta Herrmann Foundation. Vincent De Coninck is supported by the EUSP scholarship from the European Association of Urology and by a grant from the Belgische Vereniging voor Urologie (BVU).

\section{Acknowledgements}

We wish to thank Philippe Autier, MD, MPH, PhD, Senior Faculty of the International Prevention Research Institute in Lyon for statistical assistance and review.

\section{Authors' contribution}

EXK: Protocol/project development, Data analysis and Manuscript writing/editing VDC: Protocol/project development, Data analysis and Manuscript writing/editing MA: Manuscript writing/editing

SD: Data analysis and Manuscript writing/editing

MD: Protocol/project development, Data collection or management, Data analysis and Manuscript writing/editing

OT: Protocol/project development, Data analysis and Manuscript writing/editing

\section{Ethical approval}

All procedures performed in studies involving human participants were in accordance with the ethical standards of the institutional and/or national research committee and with the 1964 Helsinki declaration and its later amendments or comparable ethical standards. 


\section{References}

1. Hesse A, Brandle E, Wilbert D, Kohrmann KU, Alken P (2003) Study on the prevalence and incidence of urolithiasis in Germany comparing the years 1979 vs. 2000. Eur Urol 44 (6):709-713

2. Daudon M, Traxer O, Lechevallier E, Saussine C (2008) Epidemiology of urolithiasis. Prog Urol 18 (12):802-814. doi:10.1016/j.purol.2008.09.029

3. Yallappa S, Amer T, Jones P, Greco F, Tailly T, Somani BK, Umez-Eronini N, Aboumarzouk OM (2018) Natural History of Conservatively Managed Ureteral Stones: Analysis of 6600 Patients. J Endourol 32 (5):371-379. doi:10.1089/end.2017.0848

4. Hubner WA, Irby P, Stoller ML (1993) Natural history and current concepts for the treatment of small ureteral calculi. Eur Urol 24 (2):172-176

5. Ueno A, Kawamura T, Ogawa A, Takayasu H (1977) Relation of spontaneous passage of ureteral calculi to size. Urology 10 (6):544-546

6. Coll DM, Varanelli MJ, Smith RC (2002) Relationship of spontaneous passage of ureteral calculi to stone size and location as revealed by unenhanced helical CT. AJR Am J Roentgenol 178 (1):101-103. doi:10.2214/ajr.178.1.1780101

7. Miller OF, Kane CJ (1999) Time to stone passage for observed ureteral calculi: a guide for patient education. J Urol 162 (3 Pt 1):688-690; discussion 690-681

8. Turk C, Petrik A, Sarica K, Seitz C, Skolarikos A, Straub M, Knoll T (2016) EAU Guidelines on Diagnosis and Conservative Management of Urolithiasis. Eur Urol 69

(3):468-474. doi:10.1016/j.eururo.2015.07.040

9. Turk C, Neisius AP, A., Seitz C, Skolarikos A, Knoll T EAU Guidelines on Urolithiasis, last update march 2018. Available at:

https://uroweb.org/guideline/urolithiasis. Accessed September 25, 2018

10. Assimos D, Krambeck A, Miller NL, Monga M, Murad MH, Nelson CP, Pace KT, Pais VM, Jr., Pearle MS, Preminger GM, Razvi H, Shah O, Matlaga BR (2016) Surgical Management of Stones: American Urological Association/Endourological Society Guideline, PART I. J Urol 196 (4):1153-1160. doi:10.1016/j.juro.2016.05.090

11. Skolarikos A, Laguna MP, Alivizatos G, Kural AR, de la Rosette JJ (2010) The role for active monitoring in urinary stones: a systematic review. J Endourol 24 (6):923-930. doi:10.1089/end.2009.0670

12. Ohkawa M, Tokunaga S, Nakashima T, Yamaguchi K, Orito M, Hisazumi H (1993) Spontaneous passage of upper urinary tract calculi in relation to composition. Urol Int 50 (3):153-158. doi:10.1159/000282474

13. Sutor DJ, Wooley SE (1975) Some data on urinary stones which were passed. $\mathrm{Br}$ J Urol 47 (2):131-135 
14. Daudon M, Dessombz A, Frochot V, Letavernier $E$, Haymann J-P, Jungers $P$, Bazin D (2016) Comprehensive morpho-constitutional analysis of urinary stones improves etiological diagnosis and therapeutic strategy of nephrolithiasis. C R Chim 19 (11-12):1470-1491. doi:10.1016/j.crci.2016.05.008

15. Daudon M, Jungers $P$ (2012) Stone Composition and Morphology: A Window on Etiology. In: Talati JJ TH, Albala DM, Ye Z (ed) Urolithiasis: Basic Science and Clinical Practice. Springer, London, pp 113-140. doi:10.1007/978-1-4471-4387-1_15

16. Morse RM, Resnick MI (1991) Ureteral calculi: natural history and treatment in an era of advanced technology. J Urol 145 (2):263-265

17. Preminger GM, Tiselius HG, Assimos DG, Alken P, Buck AC, Gallucci M, Knoll T, Lingeman JE, Nakada SY, Pearle MS, Sarica K, Turk C, Wolf JS, Jr., American Urological Association E, Research I, European Association of U (2007) 2007 Guideline for the management of ureteral calculi. Eur Urol 52 (6):1610-1631

18. Tchey DU, Ha YS, Kim WT, Yun SJ, Lee SC, Kim WJ (2011) Expectant Management of Ureter Stones: Outcome and Clinical Factors of Spontaneous Passage in a Single Institution's Experience. Korean J Urol 52 (12):847-851. doi:10.4111/kju.2011.52.12.847

19. Sfoungaristos S, Kavouras A, Perimenis $P$ (2012) Predictors for spontaneous stone passage in patients with renal colic secondary to ureteral calculi. Int Urol Nephrol 44 (1):71-79. doi:10.1007/s11255-011-9971-4

20. Kishore TA, Pedro RN, Hinck B, Monga M (2008) Estimation of size of distal ureteral stones: noncontrast CT scan versus actual size. Urology 72 (4):761-764. doi:10.1016/j.urology.2008.05.047

21. Daudon M, Dore JC, Jungers $P$, Lacour B (2004) Changes in stone composition according to age and gender of patients: a multivariate epidemiological approach. Urol Res 32 (3):241-247. doi:10.1007/s00240-004-0421-y

22. Daudon M, Bouzidi H, Bazin D (2010) Composition and morphology of phosphate stones and their relation with etiology. Urol Res 38 (6):459-467. doi:10.1007/s00240010-0320-3

23. Kenney WL, Chiu P (2001) Influence of age on thirst and fluid intake. Med Sci Sports Exerc 33 (9):1524-1532

24. Daudon M, Jungers $P$, Bazin D, Williams JC, Jr. (2018) Recurrence rates of urinary calculi according to stone composition and morphology. Urolithiasis. doi:10.1007/s00240-018-1043-0

25. Maalouf NM (2011) Metabolic syndrome and the genesis of uric acid stones. $J$ Ren Nutr 21 (1):128-131. doi:10.1053/j.jrn.2010.10.015

26. Tailly $T$, Larish $Y$, Nadeau B, Violette $P$, Glickman L, Olvera-Posada D, Alenezi H, Amann J, Denstedt J, Razvi H (2016) Combining Mean and Standard Deviation of Hounsfield Unit Measurements from Preoperative CT Allows More Accurate 
Prediction of Urinary Stone Composition Than Mean Hounsfield Units Alone. J Endourol 30 (4):453-459. doi:10.1089/end.2015.0209

27. Patel SR, Haleblian G, Zabbo A, Pareek G (2009) Hounsfield units on computed tomography predict calcium stone subtype composition. Urol Int 83 (2):175-180. doi:10.1159/000230020

28. Saw KC, McAteer JA, Monga AG, Chua GT, Lingeman JE, Williams JC, Jr. (2000) Helical CT of urinary calculi: effect of stone composition, stone size, and scan collimation. AJR Am J Roentgenol 175 (2):329-332. doi:10.2214/ajr.175.2.1750329

29. Pak CY, Poindexter JR, Peterson RD, Heller HJ (2004) Biochemical and physicochemical presentations of patients with brushite stones. J Urol 171 (3):10461049. doi:10.1097/01.ju.0000104860.65987.4a 


\section{Figure legends}

\section{Figure 1}

Distribution of cases over age groups according to sex (A) and stone composition (B). $\mathrm{COM}=$ calcium oxalate monohydrate $; \mathrm{COD}=$ calcium oxalate dihydrate; $\mathrm{UAO}=$ anhydrous uric acid; UA2 = uric acid dihydrate; $\mathrm{CA}=$ carbapatite; $\mathrm{STR}=$ struvite; $\mathrm{BR}$ $=$ brushite $;$ CYS = cystine.

\section{Figure 2}

Distribution of stone size parameters (maximal stone diameter in A and stone volume in B) over stone composition categories. Boxplots are median (line), interquartile range (box) and $97.5^{\text {th }} / 2.5^{\text {th }}$ percentiles (whiskers). Mean and geometric mean values are shown as " + " in $\mathrm{A}$ and $\mathrm{B}$, respectively; $\mathrm{COM}=$ calcium oxalate monohydrate $; \mathrm{COD}=$ calcium oxalate dihydrate; $\mathrm{UA} 0=$ anhydrous uric acid; $\mathrm{UA} 2=$ uric acid dihydrate; $\mathrm{CA}=$ carbapatite $; \mathrm{STR}=$ struvite; $\mathrm{BR}=$ brushite $; \mathrm{CYS}=$ cystine . 


\section{Supplementary Figure 1}

Flow diagram of stones listed in our stone database and cases available for analysis in this study. *Whenever more than two SPS were available per case, characteristics of the SPS with the largest MSD were considered.

\section{Supplementary Figure 2}

Proportion of stones with a maximal diameter of $\geq 6 \mathrm{~mm}$ per stone composition category. $\mathrm{COM}=$ calcium oxalate monohydrate; $\mathrm{COD}=$ calcium oxalate dihydrate; $\mathrm{UA} 0=$ anhydrous uric acid; $\mathrm{UA} 2=$ uric acid dihydrate $; \mathrm{CA}=$ carbapatite; $\mathrm{STR}=$ struvite; $\mathrm{BR}=$ brushite; $\mathrm{CYS}=$ cystine .

\section{Supplementary Figure 3}

Distribution of stones with a MSD $\geq 6 \mathrm{~mm}$ over age groups, separately for each stone composition category. $\mathrm{COM}=$ calcium oxalate monohydrate $\mathrm{COD}=$ calcium oxalate dihydrate; $\mathrm{UA} 0$ = anhydrous uric acid; $\mathrm{UA} 2$ = uric acid dihydrate; $\mathrm{CA}$ = carbapatite; $\mathrm{STR}=$ struvite; $\mathrm{BR}=$ brushite; $\mathrm{CYS}=$ cystine . 
Table 1: Patient and stone characteristics with stratification for stone composition

\begin{tabular}{|c|c|c|c|c|c|c|c|c|c|c|}
\hline \multirow{2}{*}{ Variable } & \multirow{2}{*}{ Total } & \multicolumn{8}{|c|}{ Stone composition* } & \multirow[b]{2}{*}{$p$} \\
\hline & & COM & COD & UAO & UA2 & CA & STR & BR & CYS & \\
\hline Cases, no. (\%) & $\begin{array}{c}18,029 \\
(100)\end{array}$ & $\begin{array}{l}11^{\prime} 126 \\
(61.7)\end{array}$ & $\begin{array}{l}3405 \\
(18.9)\end{array}$ & $\begin{array}{l}1499 \\
(8.3)\end{array}$ & $\begin{array}{l}321 \\
(1.8)\end{array}$ & $\begin{array}{l}1362 \\
(7.6)\end{array}$ & $\begin{array}{c}54 \\
(0.3)\end{array}$ & $\begin{array}{l}156 \\
(0.9)\end{array}$ & $\begin{array}{l}106 \\
(0.6)\end{array}$ & - \\
\hline $\begin{array}{l}\text { Age, mean }(S D) \text {, } \\
\text { years }\end{array}$ & $\begin{array}{c}45 \\
(14)\end{array}$ & $\begin{array}{c}46 \\
(13)\end{array}$ & $\begin{array}{c}39 \\
(13)\end{array}$ & $\begin{array}{c}59 \\
(13)\end{array}$ & $\begin{array}{l}57 \\
(13)\end{array}$ & $\begin{array}{c}41 \\
(14)\end{array}$ & $\begin{array}{c}56 \\
(19)\end{array}$ & $\begin{array}{c}45 \\
(15)\end{array}$ & $\begin{array}{c}41 \\
(17)\end{array}$ & $<0.001$ \\
\hline $\begin{array}{l}\text { Male / Female } \\
\text { ratio }\end{array}$ & 3.01 & 3.03 & 5.09 & 3.93 & 4.73 & 0.88 & 1.00 & 4.20 & 1.94 & $<0.001$ \\
\hline $\begin{array}{l}\text { Maximal stone } \\
\text { diameter, mean } \\
\text { (SD), mm }\end{array}$ & $\begin{array}{c}4.1 \\
(2.2)\end{array}$ & $\begin{array}{l}3.6 \\
(1.8)\end{array}$ & $\begin{array}{c}4.5 \\
(2.1)\end{array}$ & $\begin{array}{l}5.5 \\
(2.9)\end{array}$ & $\begin{array}{c}4.6 \\
(2.7)\end{array}$ & $\begin{array}{c}4.9 \\
(2.6)\end{array}$ & $\begin{array}{c}7.9 \\
(3.9)\end{array}$ & $\begin{array}{c}6.2 \\
(2.4)\end{array}$ & $\begin{array}{c}6.8 \\
(3.4)\end{array}$ & $<0.001$ \\
\hline $\begin{array}{l}\text { Stone volume, } \\
\text { geometric mean } \\
\text { (SD), } \mathrm{mm}^{3}\end{array}$ & $\begin{array}{l}11.5 \\
(3.5)\end{array}$ & $\begin{array}{c}9.0 \\
(3.1)\end{array}$ & $\begin{array}{l}14.0 \\
(3.4)\end{array}$ & $\begin{array}{l}21.0 \\
(4.0)\end{array}$ & $\begin{array}{l}12.0 \\
(4.4)\end{array}$ & $\begin{array}{l}18.3 \\
(3.9)\end{array}$ & $\begin{array}{l}61.0 \\
(4.5)\end{array}$ & $\begin{array}{l}39.4 \\
(3.1)\end{array}$ & $\begin{array}{l}42.1 \\
(3.7)\end{array}$ & $<0.001$ \\
\hline
\end{tabular}

* Ordered after the Daudon classification, considering the main crystalline constituent $(\geq 50-100 \%$ of total constituent) [15].

$\mathrm{COM}=$ calcium oxalate monohydrate $; \mathrm{COD}=$ calcium oxalate dihydrate $; \mathrm{UAO}=$ anhydrous uric acid $\mathrm{UA} 2$ = uric acid dihydrate; $\mathrm{CA}$ = carbapatite; STR = struvite; $\mathrm{BR}=$ brushite; $\mathrm{CYS}=$ cystine; $\mathrm{SD}=$ standard deviation 
Table 2: Logistic regression analysis to predict maximal stone diameter $\geq 6 \mathrm{~mm}$

\begin{tabular}{|c|c|c|c|c|}
\hline \multirow[b]{2}{*}{ Variable } & \multicolumn{2}{|l|}{ Univariable } & \multicolumn{2}{|l|}{ Multivariable ${ }^{\star \star}$} \\
\hline & OR $(95 \% \mathrm{Cl})$ & $p$ & OR $(95 \% \mathrm{Cl})$ & $p$ \\
\hline $\begin{array}{l}\text { Stone composition* } \\
\text { COM } \\
\text { COD } \\
\text { UA0 } \\
\text { UA2 } \\
\text { CA } \\
\text { STR } \\
\text { BR } \\
\text { CYS }\end{array}$ & $\begin{array}{l}1.0 \text { (Ref.) } \\
3.1(2.8-3.4) \\
5.6(4.9-6.3) \\
3.3(2.6-4.3) \\
3.7(3.2-4.2) \\
16.9(9.6-29.6) \\
10.2(7.4-14) \\
11.1(7.5-16.3)\end{array}$ & $\begin{array}{l}<0.001 \\
<0.001 \\
<0.001 \\
<0.001 \\
<0.001 \\
<0.001 \\
<0.001\end{array}$ & $\begin{array}{l}1.0 \text { (Ref.) } \\
3.9(3.5-4.3) \\
3.8(3.4-4.4) \\
2.5(1.9-3.2) \\
4.6(4.0-5.3) \\
17.1(9.1-32.4) \\
11.6(8.3-16.3) \\
13.7(9.0-20.7)\end{array}$ & $\begin{array}{l}<0.001 \\
<0.001 \\
<0.001 \\
<0.001 \\
<0.001 \\
<0.001 \\
<0.001\end{array}$ \\
\hline Age (continuous, decades) & $1.33(1.30-1.37)$ & $<0.001$ & $1.37(1.33-1.41)$ & $<0.001$ \\
\hline $\begin{array}{l}\text { Sex } \\
\text { Male } \\
\text { Female }\end{array}$ & $\begin{array}{l}1.0 \text { (Ref.) } \\
0.92 \text { (0.84-1.01) }\end{array}$ & 0.08 & $\begin{array}{l}1.0 \text { (Ref.) } \\
0.93 \text { (0.84-1.02) }\end{array}$ & 0.14 \\
\hline
\end{tabular}

* Ordered after the Daudon classification, considering the main crystalline constituent $(\geq 50-100 \%$ of total constituent) [15].

** Including all variables shown in the table.

$\mathrm{OR}=$ odds ratio $; 95 \% \mathrm{Cl}=95 \%$ confidence interval; $\mathrm{COM}=$ calcium oxalate monohydrate $; \mathrm{COD}=$ calcium oxalate dihydrate; $\mathrm{UA} 0=$ anhydrous uric acid; $\mathrm{UA} 2=$ uric acid dihydrate; $\mathrm{CA}=$ carbapatite; STR = struvite; BR = brushite; CYS = cystine 
A

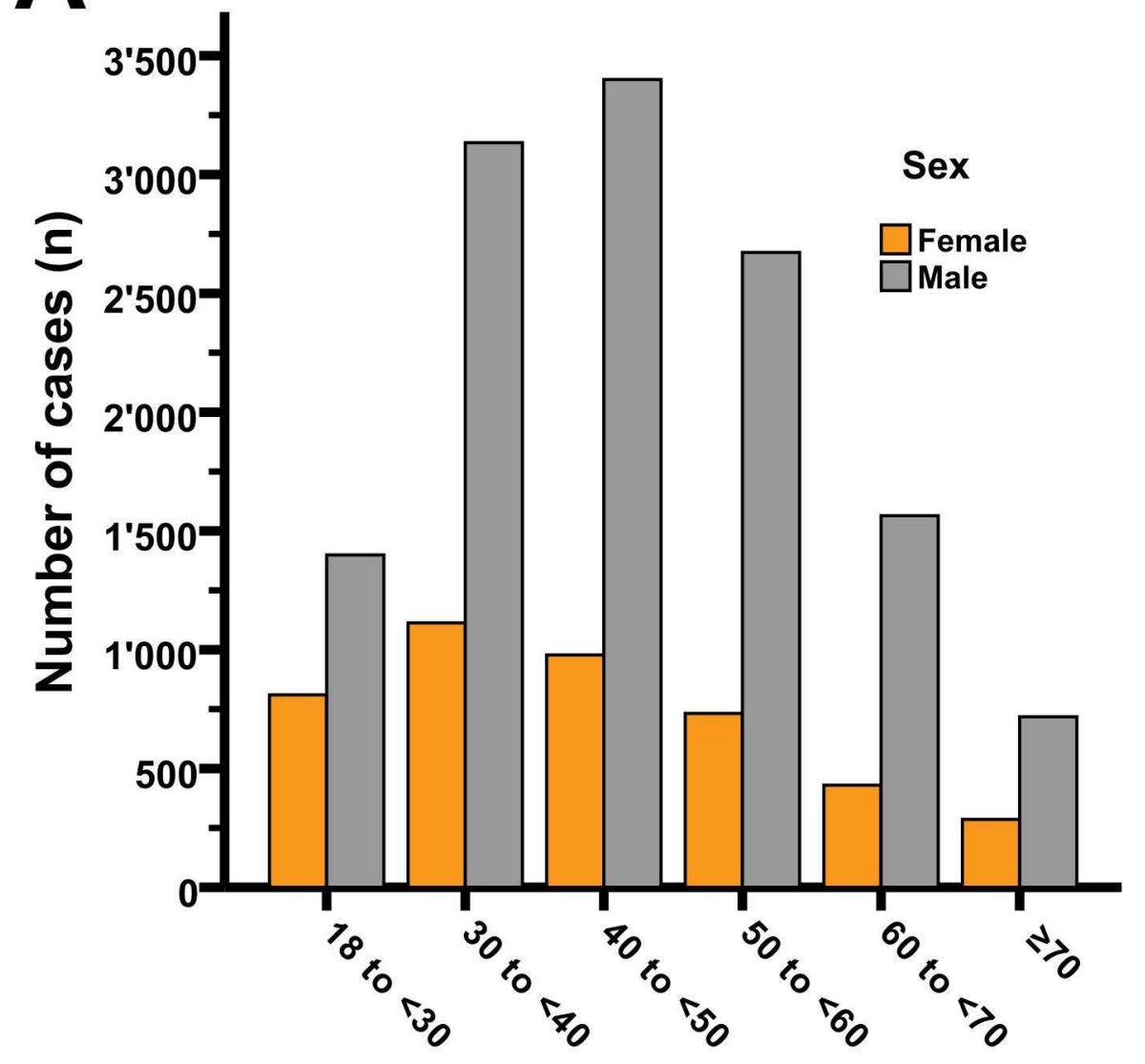

Age (years)
B

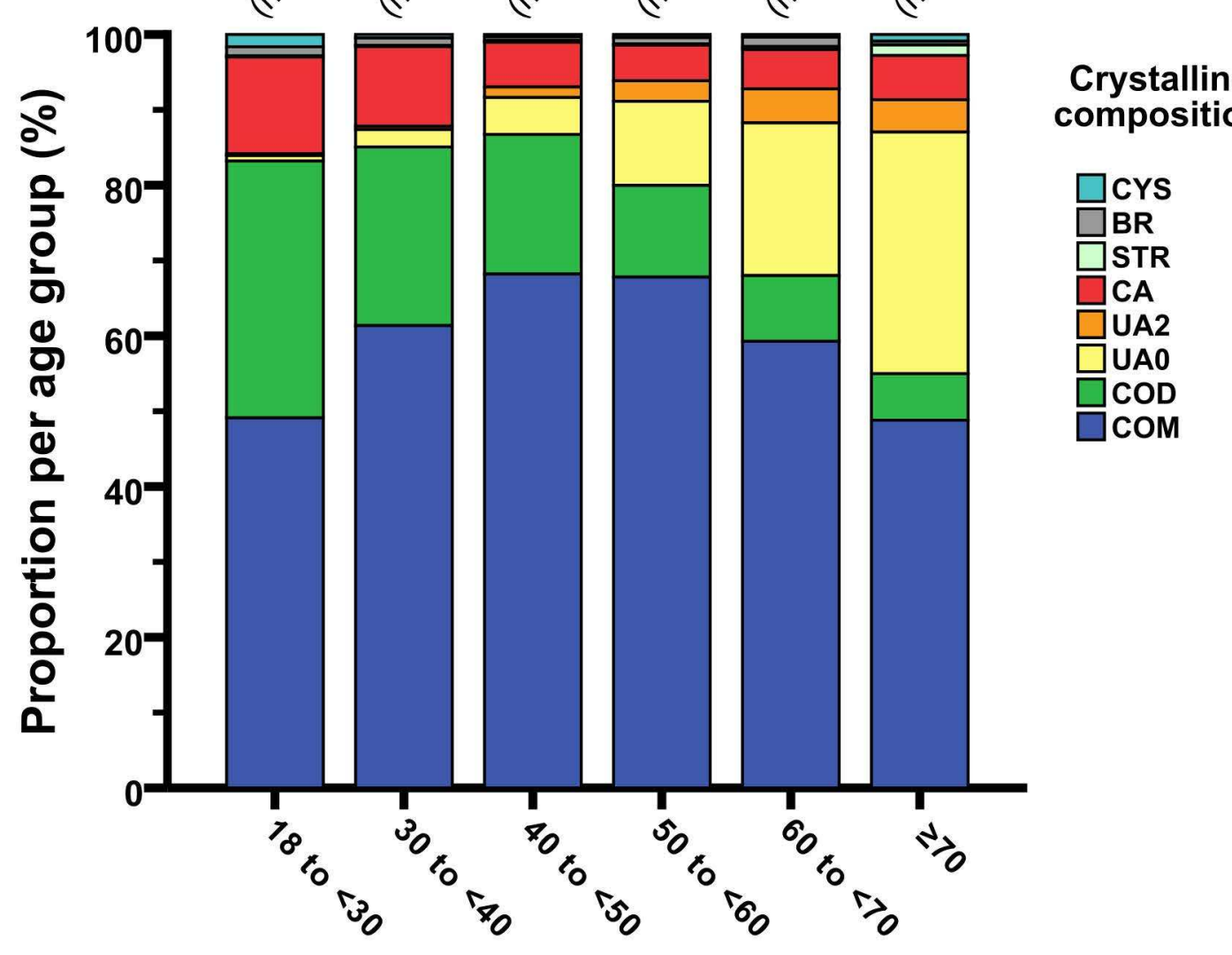

Age (years) 
A

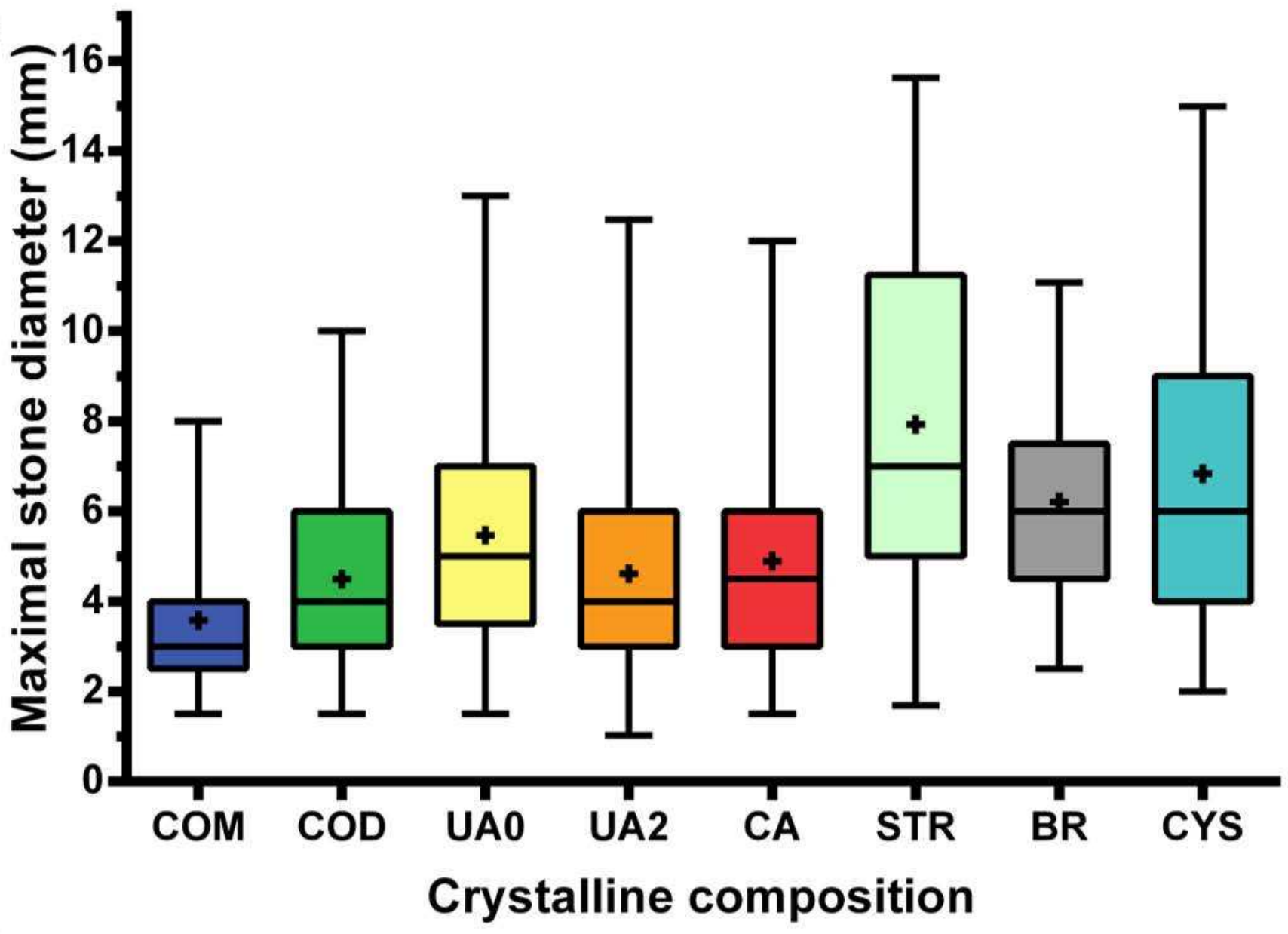

B

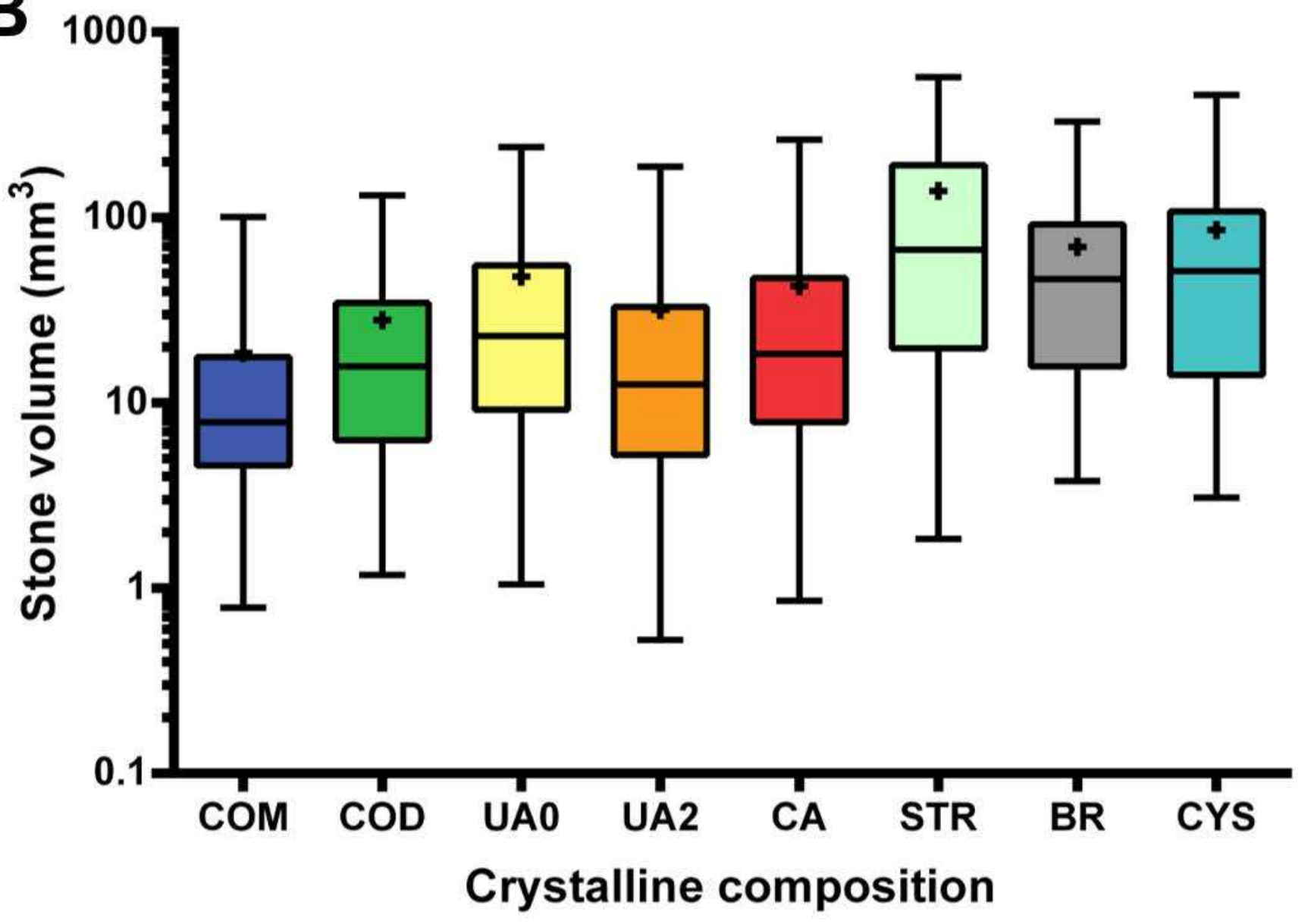


Cases in the stone database $\left(n=80^{\prime} 253\right)$

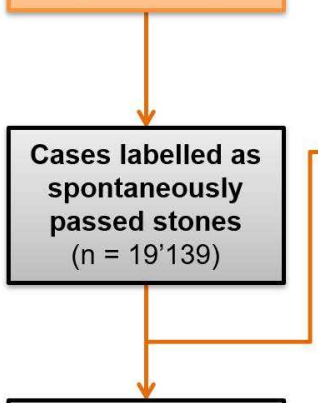

Cases eligible for analysis* $\left(n=18^{\prime} 490\right)$

Cases available for analysis $\left(n=18^{\prime} 029\right)$
Cases removed based on inclusion and exclusion criteria

$$
(n=649)
$$

- Children $<18$ years old $(n=400)$

- Location at diagnosis other than upper urinary tract $(n=63)$

- Stenotic urinary tract disease or past history of anastomotic urinary tract surgery $(n=186)$

Cases not selected based on their crystalline composition

$$
(n=461)
$$

- Indinavir $(n=41)$

- Octacalcium phosphate $(n=25)$

- Amorphous carbonated calcium phosphate $(n=23)$

- Ammonium urate $(n=22)$

- Cellulose $(n=21)$

- Mucopolysaccharide $(n=18)$

- Calcite $(n=17)$

- Atazanavir $(n=13)$

- Others $(n=281)$ 


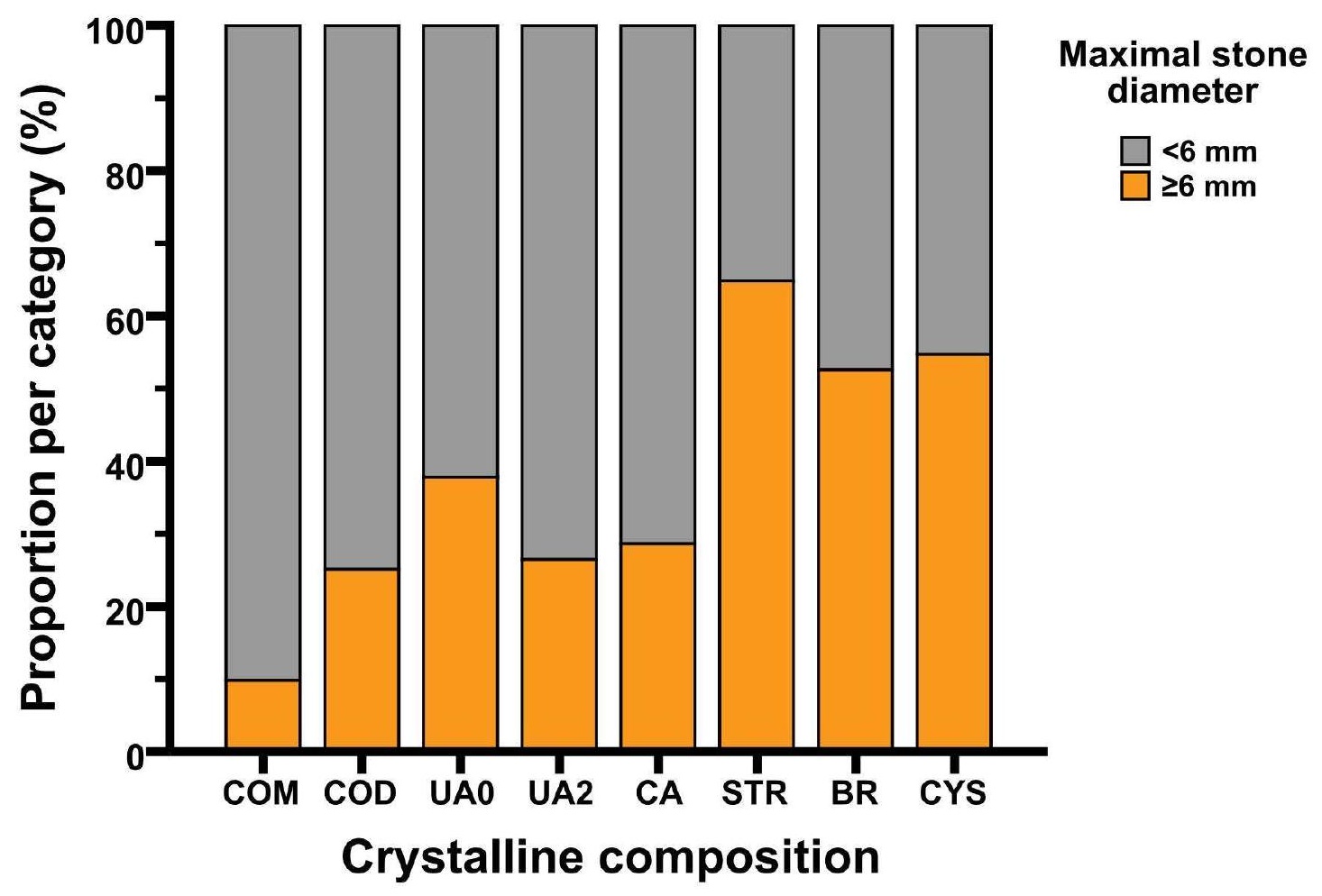


Maximal stone

diameter

$\square<6 \mathrm{~mm}$
$\square \geq 6 \mathrm{~mm}$
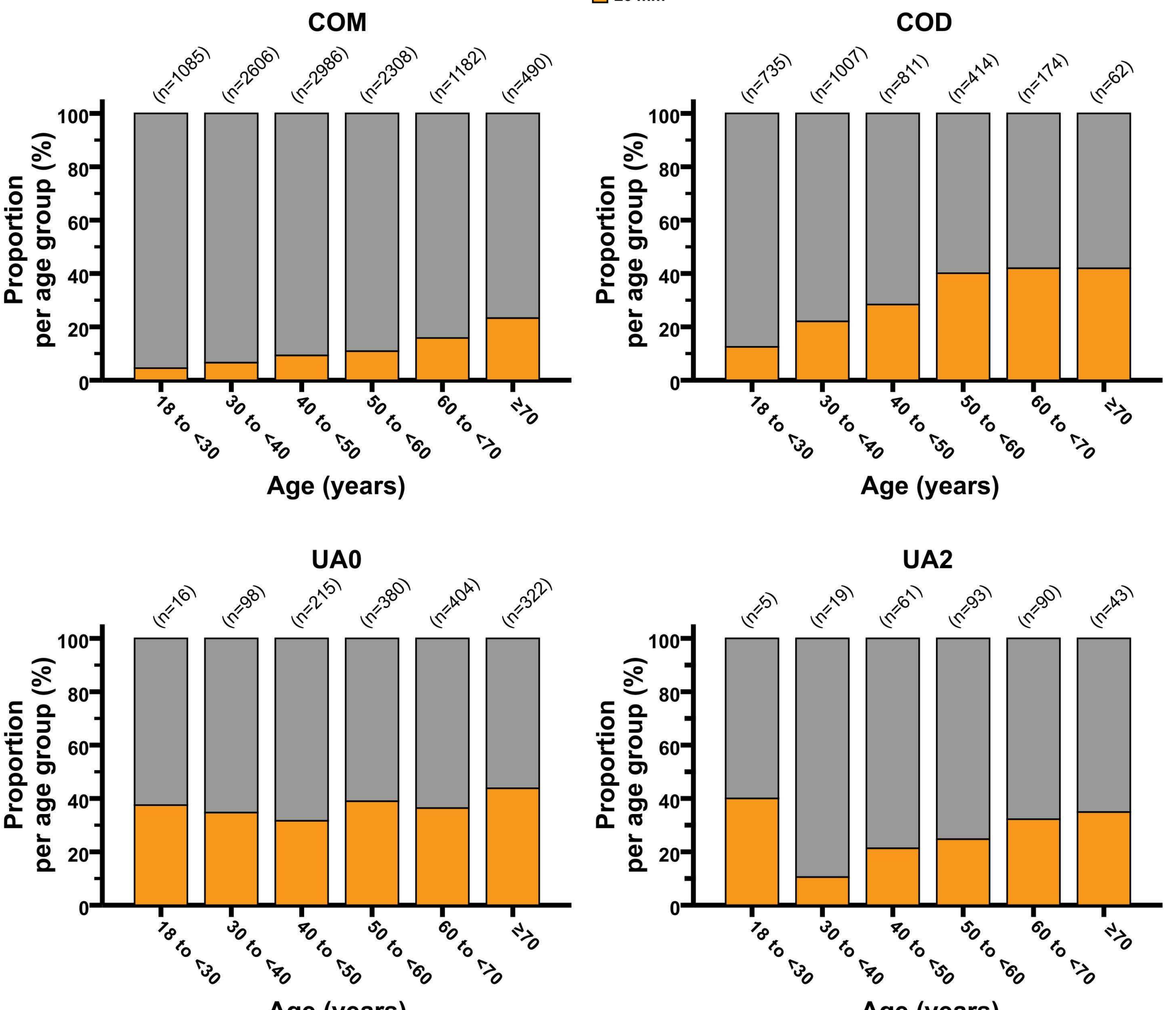

UA2
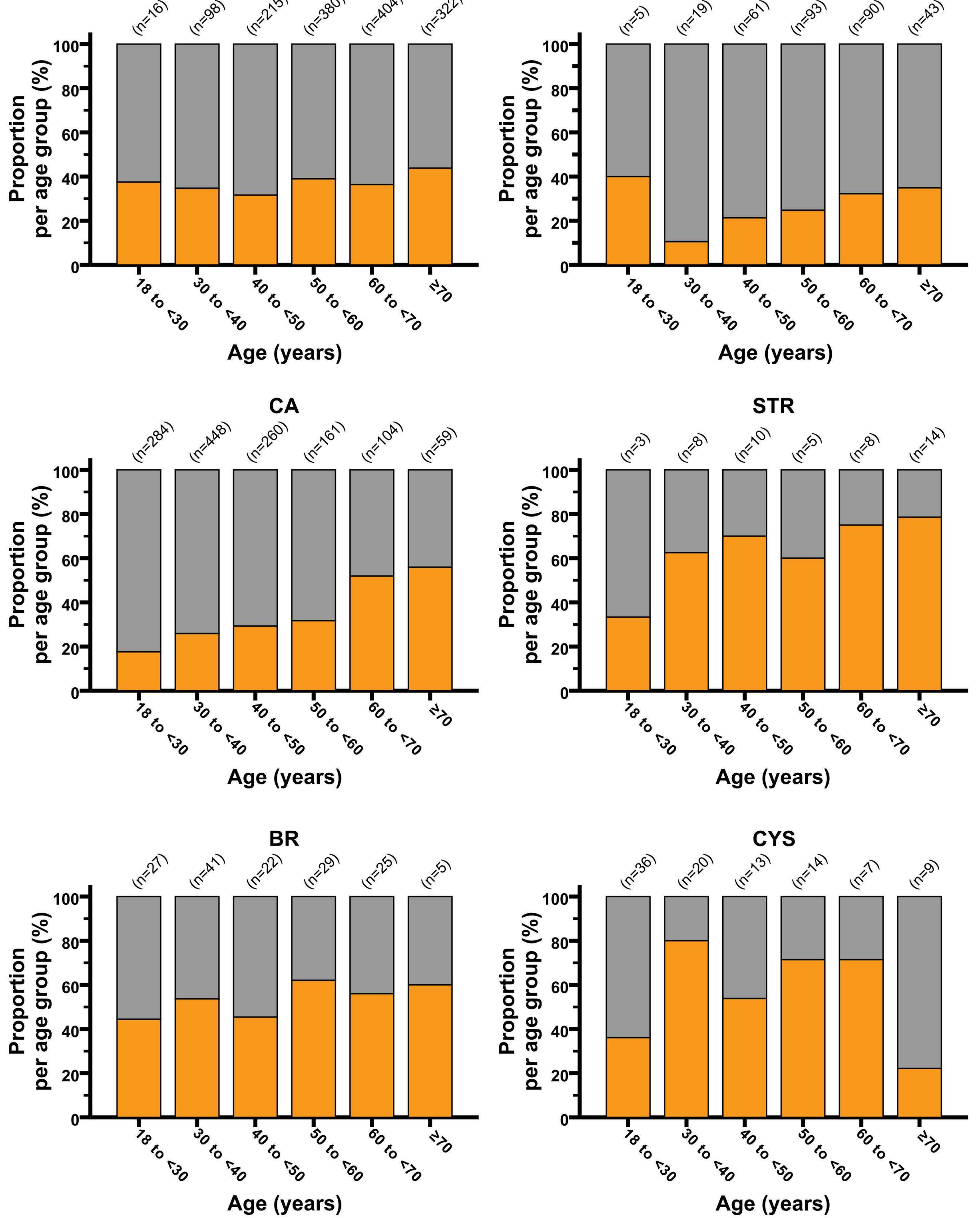